\title{
Visible-light photocatalysis over MIL-53(Fe) for VOC removal and viral inactivation in air
}

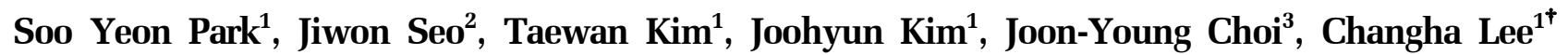 \\ ${ }^{1}$ School of Chemical and Biological Engineering, Institute of Chemical Process (ICP), and Institute of Engineering Research, Seoul National University, \\ Seoul 08826, Republic of Korea \\ ${ }^{2}$ Measurement \& Analysis Center, Environmental Infrastructure Research Department, National Institute of Environmental Research, Incheon 22689, \\ Republic of Korea \\ ${ }^{3}$ Hyorim Industries Inc., Gyeonggi-do 13517, Republic of Korea
}

\begin{abstract}
MIL-53(Fe), synthesized by a one-step hydrothermal method, was investigated for the removal of toluene and inactivation of bacteriophage $\Phi X$ 174 in air under visible light illumination. MIL-53(Fe) exhibited superior photochemical activity to other metal organic frameworks synthesized by the same method with different metal precursors. Analytical methods of diffuse reflectance spectroscopy, BET specific surface area analysis, SEM-EDS, FT-IR analysis, XRD, Mott-Schottky analysis, and XPS were used to characterize MIL-53(Fe). The illuminated MIL-53(Fe) removed input toluene $\left(\mathrm{C}_{0}=3.59 \mathrm{~g} / \mathrm{m}^{3}\right)$ by $66 \%$ in $6 \mathrm{~h}$ by adsorption and subsequent photocatalytic oxidation. High humidity and temperature, and the anoxic condition inhibited the toluene removal. MIL-53(Fe) showed sustainable toluene removal for five consecutive runs, even though the photocatalytic activity slightly decreased. Meanwhile, the illuminated MIL-53(Fe) also resulted in the inactivation of $\Phi$ X 174 suspended in air, achieving approximately $3 \mathrm{log}$ inactivation in $60 \mathrm{~min}\left(\mathrm{~N}_{0}=\sim 10^{6} \mathrm{PFU} / \mathrm{mL}\right.$ air). Similar to toluene removal, the presence of oxygen and low humidity were beneficial for viral inactivation. The photo-generated holes are believed to be responsible for the organic degradation and viral inactivation by the illuminated MIL-53(Fe).
\end{abstract}

Keywords: Metal-organic frameworks, MIL-53(Fe), Photocatalysis, Virus inactivation, Visible-light photocatalyst, Volatile organic compounds

\section{Introduction}

VOCs are important indoor air pollutants and are frequently found at higher concentrations than outdoors [1-3]. A variety of VOCs can be emitted from different sources. VOCs commonly detected in indoor air include benzene, toluene, ethylbenzene, xylene, naphthalene, dichloromethane, chloroform, and acetone [2, 4-6]. These compounds are generated from different emission sources, such as aerosol sprays, paints, dry-cleaned clothing, and building construction materials [7-9]. Many VOCs are known to be toxic, and exposure to VOCs can cause detrimental effects including headache, allergic skin reaction, and carcinogenic risk [1, 10, 11].

Meanwhile, the COVID-19 pandemic has raised awareness of the airborne transmission of pathogenic microorganisms, and the resultant public health risk. Pathogenic microorganisms that are contained in dust particles and aerosol droplets circulate in air
[12-14]. These microorganisms generally include influenza virus, enterovirus, norovirus, coronavirus, and respiratory syncytial virus [15]. Although particles greater than $10 \mu \mathrm{m}$ quickly fall out of the air, smaller particles can be suspended, and possibly inhaled through the respiratory tract, causing harmful health effects [16].

To treat air pollutants including VOCs and airborne pathogens, three physical and chemical methods have been commonly addressed, i.e., adsorption (on porous materials such as activated carbon and zeolite), filtration, and photocatalytic oxidation [3, 17-19]. Among them, photocatalytic oxidation is a powerful tool that by chemical reactions at ambient room temperature and pressure is capable of degrading (or mineralizing) VOCs, as well as inactivating microorganisms $[6,20]$. For the photocatalytic treatment of VOCs and microorganisms, titania $\left(\mathrm{TiO}_{2}\right)$ has been most intensively studied [21-28]. However, $\mathrm{TiO}_{2}$, of which the bandgap is 3.0-3.2 eV, can only utilize UV light [6, 29], which limits versatile
This is an Open Access article distributed under the terms of the Creative Commons Attribution Non-Commercial License (http://creativecommons.org/licenses/by-nc/3.0/) which permits unrestricted non-commercial use, distribution, and reproduction in any medium, provided the original work is properly cited.

Copyright (C) 2022 Korean Society of Environmental Engineers
Received April 27, 2021 Accepted July 08, 2021

${ }^{\dagger}$ Corresponding author

E-mail: leechangha@snu.ac.kr

Tel: +82-2-880-8630 Fax: +82-2-888-7259

ORCID: 0000-0002-0404-9405 
applications of the photocatalyst. Extending the available wavelength of light (possibly to the visible light region) can offer the photocatalytic system that works under indoor lighting conditions (artificial lighting and natural daylighting). Several visible light-active photocatalysts based on $\mathrm{WO}_{3}, \mathrm{~g}-\mathrm{C}_{3} \mathrm{~N}_{4}, \mathrm{~V}_{2} \mathrm{O}_{5}$, and $\mathrm{In}_{2} \mathrm{O}_{3}$ have been studied for the treatment of VOCs and microorganisms in air [30-36].

In this study, metal-organic frameworks (MOFs) were tested as visible light-photocatalysts for air treatment. In the past decade, MOFs have been extensively studied for various applications that include environmental cleanup [37, 38]. Owing to their extra-high porosity, ordered structures, and adjustable chemical functionalities, MOFs have been frequently suggested as adsorbents to remove organic contaminants and heavy metals [39-41]. Some MOFs also exhibited photocatalytic activity to degrade organic contaminants [42-45]. However, the photocatalytic applications of MOFs in air cleaning have rarely been reported. A few MOFs have been tested for toluene removal (MLL-88B, [46]) and E. coli inactivation (ZIF-8, [47]) in air under simulated solar illumination.

MIL-53(X) has attracted attention due to its simple structure, and "breathing effect" upon the adsorption and desorption of water and other gases [48-52]. Compared to its chromium and aluminum analogues, MIL-53(Fe) in particular showed the greater breathing characteristic [52]. To date, MIL-53(X) has been examined only in aqueous system for the degradation of organic compounds [53-55]; to the best of our knowledge, no study has reported photocatalytic air treatment using MIL-53(X).

The objectives of this study were to assess the visible light-photocatalytic activity of ML-53(X) (mainly ML-53(Fe)) for VOC removal and viral inactivation in air, and to evaluate potential parameters affecting the performance of the photocatalytic treatment. For the photocatalytic experiments, toluene and bacteriophage $\Phi X 174$ were chosen as a model VOC and a surrogate virus, respectively. The removal of toluene and the inactivation of $\Phi X 174$ were examined under different conditions of relative humidity, atmospheric oxygen, and temperature. Based on the obtained results, the photocatalytic mechanisms were discussed.

\section{Materials and Methods}

\subsection{Reagents}

All chemicals were of reagent grade and were used without further purification. The chemicals used in this study included nickel(II) nitrate hexahydrate, copper(II) nitrate trihydrate, cobalt(II) nitrate hexahydrate, iron(III) chloride hexahydrate $\left(\mathrm{FeCl}_{3} \cdot 6 \mathrm{H}_{2} \mathrm{O}\right)$, terephthalic acid $\left(\mathrm{H}_{2} \mathrm{BDC}\right)$, toluene, acetaldehyde, ethanol, sodium sulfate, chitosan, sodium chloride, magnesium sulfate heptahydrate, potassium phosphate monobasic, sodium hydroxide, Nafion ${ }^{\circledR}$ perfluorinated resin solution, 2,3-bis(2-methyl-4-nitro-5-sulfophenyl)2H-tetrazolium-5-carboxanilide (XTT), and 5,5-dimethyl-1-pyrroline N-oxide (DMPO) (all obtained from Sigma-Aldrich). Other materials used were N,N-dimethylformamide (DMF, from Alfa Aesar), methanol (from Honeywell), nutrient broth, and agar (from Becton-Dickinson). Deionized (DI) water (> 18.2 M $2 \cdot \mathrm{cm})$ produced by a Milli-Q Water Purification System (Millipore) was used to prepare all solutions.

\subsection{Culture and Analysis of $\Phi \mathrm{X} 174$}

The culture and analysis of bacteriophage $\Phi X 174$ (ATCC 13706-B1) was conducted following the ATCC manual [56]. The host E. coli (ATCC 13706) was cultivated in the medium containing $8 \mathrm{~g} / \mathrm{L} \mathrm{nu-}$ trient broth and $5 \mathrm{~g} / \mathrm{L} \mathrm{NaCl}$. $\Phi X 174$ was inoculated in the suspension of host E. coli cells for $18-24 \mathrm{~h}$ at $37^{\circ} \mathrm{C}$. The mixture of $E$. coli and $\Phi X 174$ was centrifuged at 33,000 g for $15 \mathrm{~min}$, to separate $\Phi X 174$ in the supernatant. The population of $\Phi X 174$ was quantified by the plaque assay method using media of the top and bottom double layer containing $0.5 \%$ and $1.5 \%$ of agar. The stock suspension of $\Phi X 174$ contained approximately $10^{6} \mathrm{PFU} / \mathrm{mL}$.

\subsection{Synthesis}

ML-53(X) was prepared according to the previously reported method [53]. Briefly, the metal salt (i.e., nickel(II) nitrate hexahydrate, copper(II) nitrate trihydrate, cobalt(II) nitrate hexahydrate, and iron(III) chloride hexahydrate), $\mathrm{H}_{2} \mathrm{BDC}$, and DMF were mixed in molar ratios of 1:1:280. The mixture was transferred into a Teflon-lined autoclave and heated at $150^{\circ} \mathrm{C}$ for $15 \mathrm{~h}$. After cooling the autoclave to room temperature, the resulting mixture was washed three times with methanol. The obtained powder was then dried at $60^{\circ} \mathrm{C}$ overnight.

\subsection{Characterization}

$\mathrm{X}$-ray diffraction patterns of the synthesized materials were recorded by X-ray diffractometry (SmartLab, Rigaku) with $\mathrm{Cu}-\mathrm{K} \alpha$ radiation. The obtained signal was compared through a computer simulation program (Mercury), and the CIF file for the simulation program was taken from Millange et al. [52]. Morphology and surface elemental distribution were analyzed by field emission scanning electron microscopy, coupled with energy dispersive X-ray spectrometry (FE-SEM/EDS, JSM-7800F Prime, Jeol). The specific surface area and pore structure were analyzed by BET-surface area analysis (ASAP 2020, Micromeritics). Diffuse reflectance spectra were obtained by UV/Vis/Near IR spectrophotometry (Cary 5000, Agilent). X-ray photoelectron spectroscopy (XPS, AXIS Supra, Kratos) and Fourier transform infrared spectroscopy (FT-IR, Frontier, PerkinElmer) were used to examine the surface compositions and functional groups of the powered products. Mott-Schottky measurements were conducted by potentiostat (VSP, Bio-Logic Science Instruments). The ML-53(Fe) photo-electrode was prepared according to the method reported by Zhao et al. [57], with a slight modification as follows: The ML-53(Fe) powder ( $0.1 \mathrm{~g}$ ) was dispersed in $1 \mathrm{~mL}$ chitosan solution (10 g/L), and ultrasonicated for $30 \mathrm{~min}$. Then, the colloidal solution was coated on the indium-doped tin oxide (ITO) surface $(5 \mathrm{~cm} \times 4.5 \mathrm{~cm})$ using the Doctor blade method, and dried at room temperature overnight. The measurements were performed in a standard three-electrode system (the MIL-53(Fe)-coated ITO as a working electrode, Pt foil as a counter electrode, and saturated calomel electrode (SCE) as a reference electrode) with $0.5 \mathrm{M} \mathrm{Na}_{2} \mathrm{SO}_{4}$ solution as the electrolyte. A 150 W xenon arc lamp (LS 150, Abet Technologies) was used as a light source, together with an AM 1.5 G filter and a UV-cutoff filter $(400 \mathrm{~nm})$. 


\subsection{Setup and Procedure for Photocatalytic Experiments}

All experiments were conducted with illuminating visible light onto the MIL-53(X)-coated glass plate in a photo-reactor (a $45 \mathrm{~mL}$ stain-less steel chamber with a round quartz window (4 $\mathrm{cm}$ radius), refer to Fig. S1 of the Supplementary Data (SD)). The MLL-53(X)-coated glass plate $(3.5 \mathrm{~cm} \times 5 \mathrm{~cm})$ was prepared using the Doctor blade method; $\mathrm{ML}-53(\mathrm{X})$ was coated on the plate using $0.15 \mathrm{~g} / \mathrm{mL}$ suspension in ethanol, then dried at room temperature for $1 \mathrm{~h}$, and subsequently at $200^{\circ} \mathrm{C}$ for $1 \mathrm{~h}$. The light illumination was performed using a $150 \mathrm{~W}$ xenon arc lamp (LS 150, Abet Technologies) equipped with an AM $1.5 \mathrm{G}$ filter and a $400 \mathrm{~nm}$ UV-cutoff filter; the incident light intensity was adjusted to 100 $\mathrm{mW} / \mathrm{cm}^{2}$ without the UV-cutoff filter.

For the experiments, an aliquot of the liquid organic compound (mainly toluene, and acetaldehyde for some experiments) or the $\Phi X 174$ stock suspension was injected into the sealed photo-reactor with the MIL-53(X)-coated glass plate. The reactor was stabilized until the liquid in the reactor was completely evaporated (30 min for the organic compound, and $2 \mathrm{~d}$ for the $\Phi \mathrm{X} 174$ stock suspension). The photocatalytic reaction was initiated by light illumination. Samples were taken at predetermined time intervals using a 100 $\mu \mathrm{L}$ gas-tight syringe (Hamilton). The concentration of the organic compound was measured by gas chromatography equipped with flame ionization detector (GC-FID, Agilent 7820A, Agilent Technologies). The separation was performed on a HP-5 capillary column using hydrogen (by the LC- $\mathrm{H}_{2} 180$ hydrogen generator, F-DGSi), air, and nitrogen as carrier gases. In the viral inactivation experiments, the sample in the syringe was diffused into $1 \mathrm{~mL}$ phosphate buffer solution (PBS, $\mathrm{pH}$ 7.2). The population of $\Phi X 174$ in the PBS solution was quantified by the plaque assay method.

The photocatalytic experiments were conducted under different conditions of temperature and relative humidity, which were adjusted using a heating plate and a humidifier (filled with DI), respectively. Sodium sulfate was used when reducing humidity in the reactor. For some experiments, pure nitrogen or oxygen was used as the gas medium in the reactor. All experiments were performed at least in duplicate; average values and standard deviations (error bars) are presented.

To verify the photo-generation of charge carriers, photoluminescence (PL) was measured in $1 \mathrm{~g} / \mathrm{L}$ aqueous suspension of MIL-53(Fe) by spectrofluorimetry (F-7100, Hitachi). Upon excitation at $400 \mathrm{~nm}$, luminescence emission was recorded over a range of 420-500 nm. Photocurrent was also measured on the MIL-53(Fe) electrode under visible light illumination. The MLL-53(Fe) photo-electrode was prepared as follows: The ML-53(Fe) powder (0.05 g) was dispersed in $0.5 \mathrm{~mL}$ binder solution (Nafion:ethanol = 1:1), and ultrasonicated for $30 \mathrm{~min}$. Then, the colloidal solution was coated on the indium-doped tin oxide (ITO) surface $(2.3 \mathrm{~cm} \times$ $4 \mathrm{~cm}$ ) using the drop coating method, and dried at $150^{\circ} \mathrm{C}$ for 30 min. The experiments were performed in a standard three-electrode system (the MIL-53(Fe)-coated ITO as a working electrode, Pt mesh as a counter electrode, and saturated calomel electrode (SCE) as a reference electrode) in $0.1 \mathrm{M} \mathrm{Na}_{2} \mathrm{SO}_{3}$ solution.

To detect the reactive oxidants possibly generated by the photocatalytic reactions of $\mathrm{ML}-53(\mathrm{Fe})$, some experiments were performed in aqueous suspension containing MLL-53(Fe) and a spin trapping agent (DMPO for the electron paramagnetic resonance (EPR) analysis), or a probe compound (XTT) for superoxide radical anion $\left(\mathrm{O}_{2}{ }^{-}\right)$. Aqueous suspension of MLL-53(Fe) (0.5 g/L), DMPO (10 mM), or XTT $(0.1 \mathrm{mM})$ in the photo-reactor was illuminated by visible light $\left(100 \mathrm{~mW} / \mathrm{cm}^{2}\right)$. Samples were collected from the photochemical reactor, and transferred into a quartz flat cell for the EPR analysis. The signals were scanned by EPR spectrometry (JES-X310, Jeol) under the following conditions: microwave frequency at $9.42 \mathrm{GHz}$, microwave power at $1.00 \mathrm{~mW}$, modulation frequency at $100 \mathrm{kHz}$, and modulation amplitude at 2.0G. For the XTT analysis, samples were filtered using a $0.45 \mu \mathrm{m}$ PTFE syringe filter (Advantech), and the absorbance was measured by UV/visible spectrophotometry (Lambda 465, PerkinElmer). $\mathrm{O}_{2}{ }^{-}$is known to reduce XTT to form XTT-formazan, resulting in a strong visible-light absorption band at $470 \mathrm{~nm}$ [58].

\section{Results and Discussion}

\subsection{Characterization of MIL-53(Fe)}

The XRD patterns of the synthesized MIL-53(Fe) agreed well with the simulation (Fig. 1(a)), and were also consistent with those reported previously [52, 54]. In the SEM imagery, ML-53(Fe) formed lozenge-shaped particles of approximate length $4 \mu \mathrm{m}$ (Fig. 1(b)). The EDS elemental maps showed that carbon $(\mathrm{C})$, oxygen $(\mathrm{O})$, and iron (Fe) were uniformly dispersed on the particle surface with the composition of $63.11,30.98$, and 5.91 wt.\%, respectively. In the FT-IR spectrum, characteristic peaks appeared at 3,300, 1,706, 1,580, 1,450, 748, $538 \mathrm{~cm}^{-1}$ (Fig. 1(c)) which are assigned to O-H and $\mathrm{C}=\mathrm{O}$ bonds in the carboxylic acid group, $\mathrm{C}=\mathrm{C}$ and $\mathrm{C}-\mathrm{H}$ bonds in the benzene ring, and the $\mathrm{Fe}-\mathrm{O}$ bond, respectively $[55,59]$. The $\mathrm{N}_{2}$ adsorption-desorption isotherm showed that MIL-53(Fe) displays the unrestricted monolayer-multilayer adsorption characteristic (type II) (Fig. 1(d)). The BET specific surface area, total pore volume, and average pore diameter were calculated to be $1,696.1 \mathrm{~m}^{2} \mathrm{~g}^{-1}, 2.000 \mathrm{~cm}^{3} \mathrm{~g}^{-1}$, and $6.397 \mathrm{~nm}$, respectively.

The diffuse reflectance spectrum showed that MIL-53(Fe) has broad absorbance in the visible light range (Fig. 1(e)). The Kubelka-Munk function (Eq. (1)) was used to determine the band gap energy of MLL-53(Fe) [60]:

$$
\mathrm{F}(R)=\frac{(1-R)^{2}}{2 R}
$$

where, $\mathrm{R}$ is the relative reflectance ratio of the sample to the standard $\mathrm{BaSO}_{4}$. The plot of $[\mathrm{F}(R) E]^{1 / 2}$ versus $E$ (light energy) calculated the bandgap energy as $2.76 \mathrm{eV}$ (refer to the inset of Fig. 1e), which was consistent with the reported values [53]. The Mott-Schottky measurements were performed to determine the band position of MLL-53(Fe) (Fig. 1(f)). The flat-band potential of MLL-53(Fe) measured at $68,100 \mathrm{~Hz}$ was determined to be $-0.61 \mathrm{~V}$ vs. SCE (equivalent to $\left.-0.37 \mathrm{~V}_{\mathrm{NHE}}\right)$. The flat-band potential was $0.1 \mathrm{~V}$ higher than the conduction band (CB) potential for MIL-53(Fe) [55], which calculates the $\mathrm{CB}$ potential of MIL-53(Fe) as $-0.47 \mathrm{~V}_{\mathrm{NHE}}$. The valence band of MIL-53(Fe) was determined to be $+2.29 \mathrm{~V}_{\mathrm{NHE}}$. 

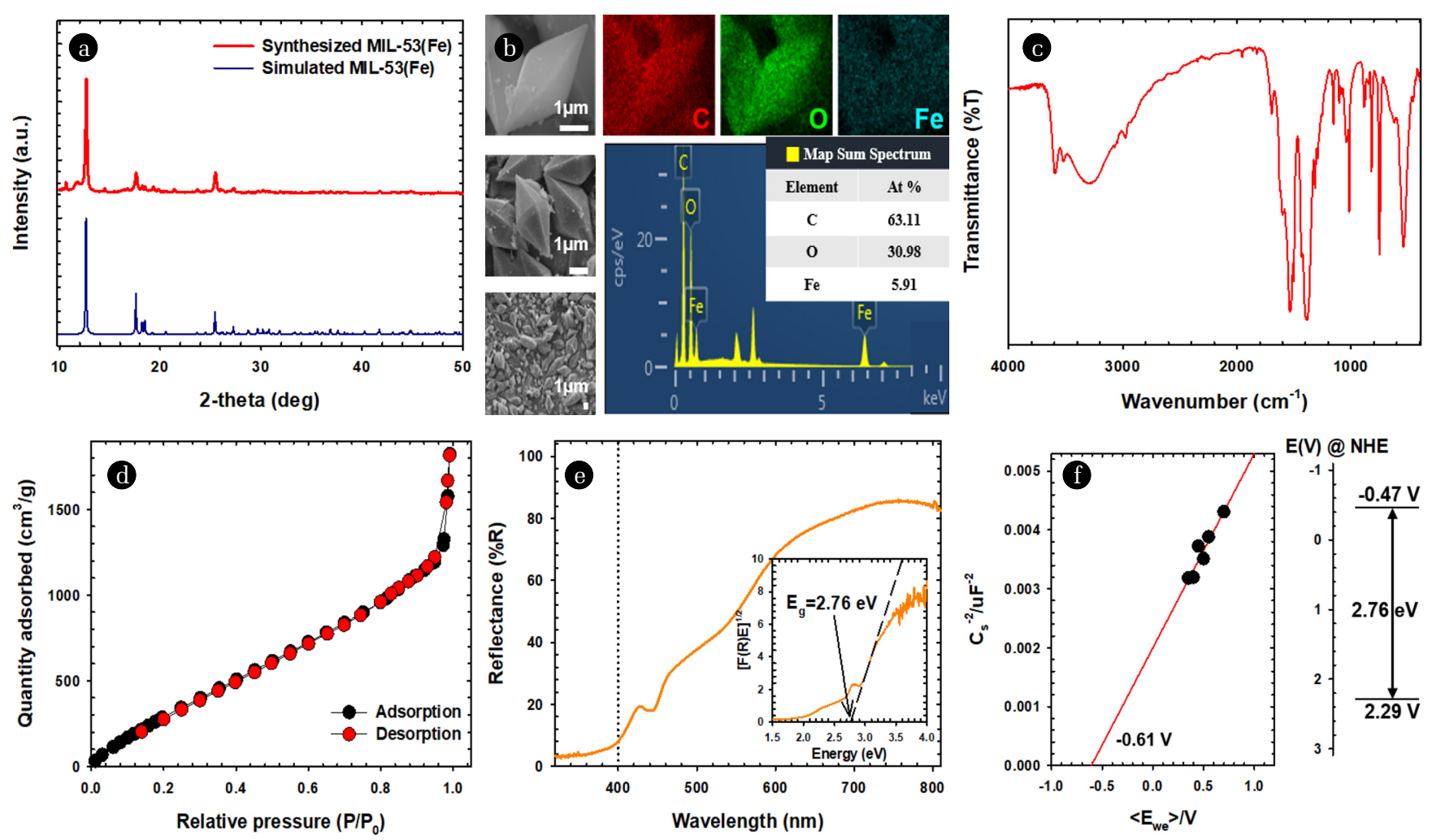

Fig. 1. (a) XRD patterns, (b) SEM-EDS images, (c) FT-IR spectrum, (d) $\mathrm{N}_{2}$ adsorption isotherm, (e) diffuse reflectance spectrum, and (f) the Mott-Schottky plot of MIL-53(Fe).
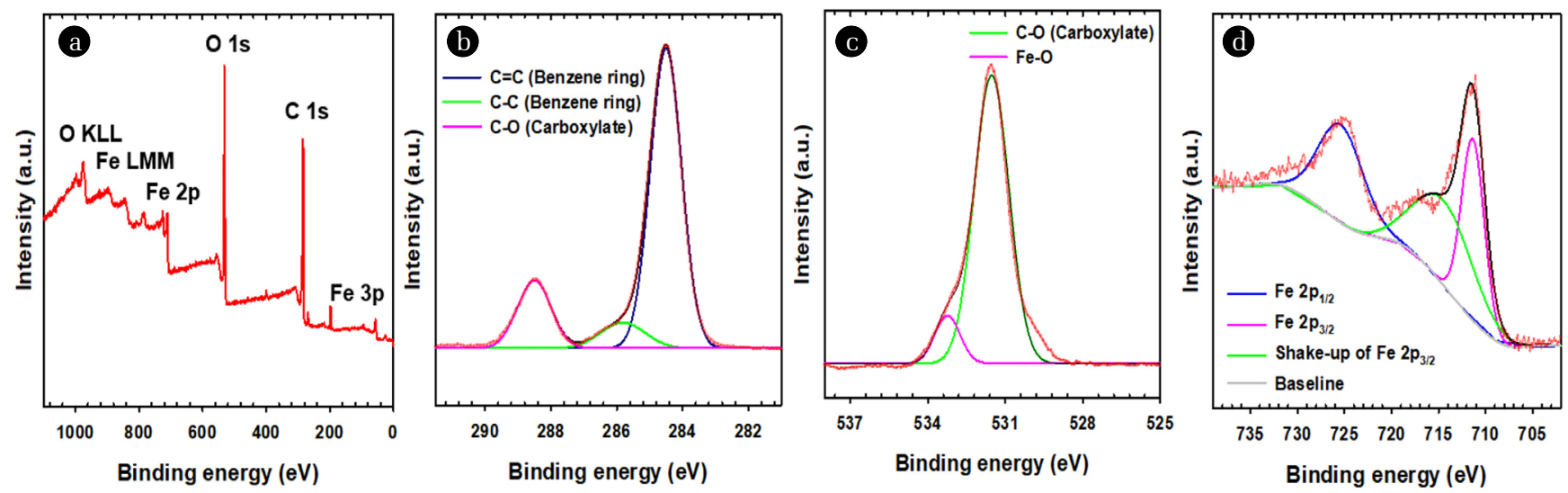

Fig. 2. XPS spectra of MIL-53(Fe): (a) the survey spectrum, and the high-resolution spectra of (b) C 1s, (c) O 1s, and (d) Fe 2p.

The XPS survey spectrum revealed that MLL-53(Fe) was composed of C, O, and Fe elements (Fig. 2(a)). The XPS C 1s spectrum exhibited three peaks at the binding energies of 284.5, 285.8, 288.5 $\mathrm{eV}$, which indicate $\mathrm{C}=\mathrm{C}$ and $\mathrm{C}-\mathrm{C}$ bonds in the benzene ring, and C-O bonds in the carboxylic acid group, respectively (Fig. 2(b)) $[55,61]$. The $\mathrm{O} 1 \mathrm{~s}$ spectrum was deconvoluted into two peaks at 531.5 and $533.2 \mathrm{eV}$, indicating $\mathrm{C}-\mathrm{O}$ bonds in the carboxylic acid group and Fe-O bonds, respectively (Fig. 2(c)) [55, 61]. In the Fe $2 p$ spectrum, two peaks assigned to $F e p_{3 / 2}$ and $F e ~ 2 p_{1 / 2}$ appeared at 711.3 and $725.4 \mathrm{eV}$, respectively (Fig. 2(d)). In the middle of the two peaks (at $715.8 \mathrm{eV}$ ), an additional peak associated with shake-up lines for metal transitions was detected [61, 62].

\subsection{Photocatalytic Removal of Organics by MIL-53(Fe)}

The photocatalytic activity of MIL-53(Fe) was evaluated for the removal of gaseous toluene under visible light illumination (Fig. $3(\mathrm{a})$ ). Toluene was removed by $26 \%$ for $6 \mathrm{~h}$ via adsorption under dark conditions. Under illumination, the toluene removal was significantly accelerated due to the photocatalytic degradation $(66 \%$ removal for $6 \mathrm{~h}$ ). The removal process of toluene followed pseudo 

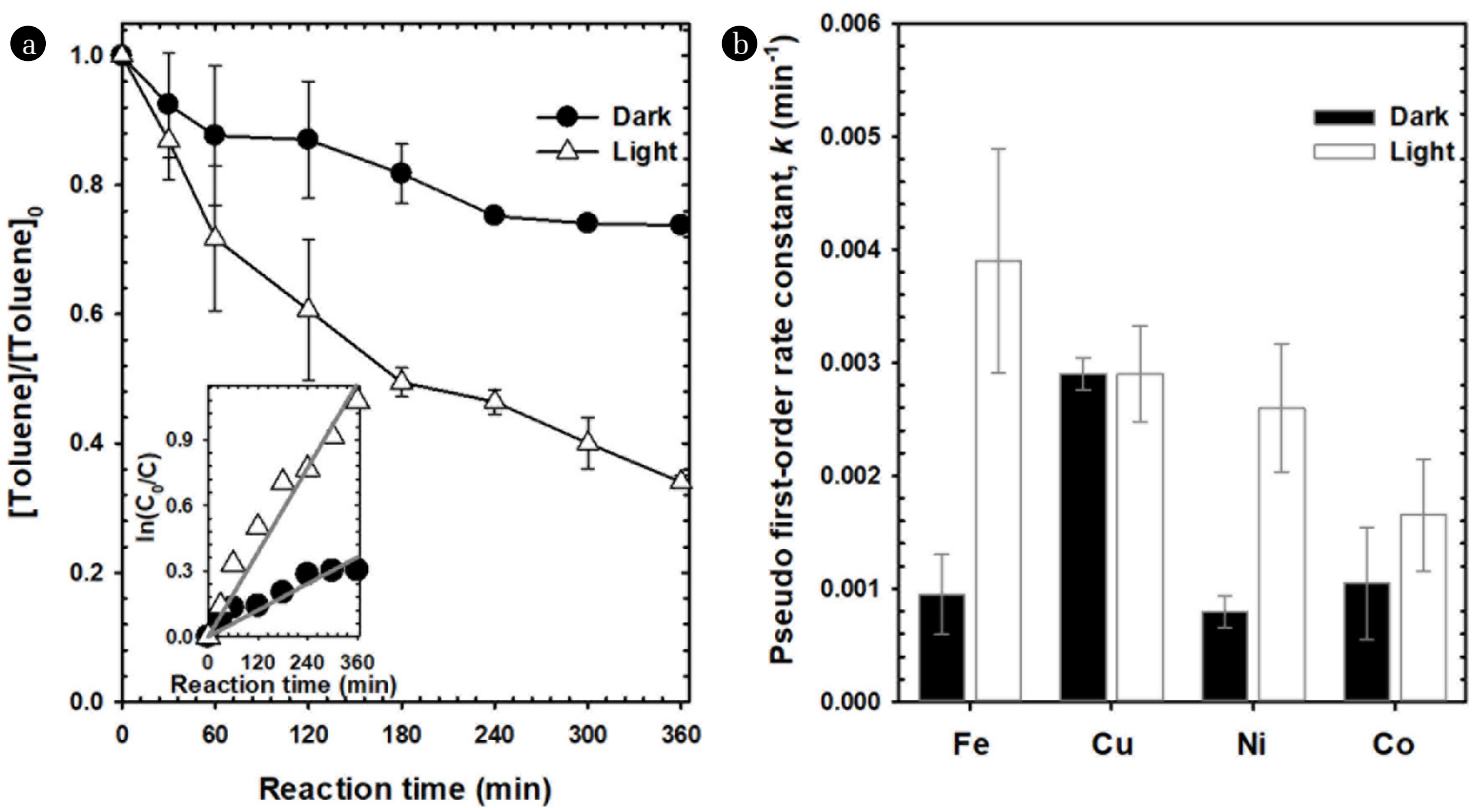

Fig. 3. (a) Removal of toluene by MIL-53(Fe) (inset: plots in log scale), and (b) pseudo first-order rate constant for the removal of toluene by different MIL-53(X) materials $(X=\mathrm{Fe}, \mathrm{Cu}, \mathrm{Ni}, \mathrm{Co})$, under dark and illuminated conditions $\left([\text { Toluene }]_{0}=3.59 \mathrm{mg} / \mathrm{L} ;[\text { Catalyst }]_{0}=0.15\right.$ $\mathrm{g} / \mathrm{mL})$.

first-order kinetics under both dark and illumination conditions (refer to the inset of Fig. 3(a)), where the observed rate constants were calculated as 0.0009 and $0.0039 \mathrm{~min}^{-1}$, respectively. In addition, the removal of gaseous acetaldehyde by $\mathrm{MLL}-53(\mathrm{Fe})$ was examined under dark and illumination conditions (Fig. S2 in the SD). Compared to toluene, acetaldehyde was removed to a greater extent by both adsorption and photocatalytic degradation, due to the lower molecular weight [63].

Similar MOF materials (MLL-53(X)) were synthesized using different metal precursors, i.e., copper, nickel, cobalt, and iron (X $=\mathrm{Cu}, \mathrm{Ni}, \mathrm{Co}$ ), and their performance for the removal of toluene was compared to that of ML-53(Fe). The pseudo first-order rate constants for the toluene removal under dark and illumination conditions are presented for each material (Fig. 3(b), refer to Fig. S3 of the SD for the time-dependent removal of toluene) Among the four materials, MIL-53(Fe) exhibited the greatest photocatalytic activity. While MIL-53(Cu) demonstrated greater adsorption capacity of toluene compared to MLL-53(Fe) (the removal under dark conditions), it did not show much photocatalytic activity.

\subsection{Effects of Temperature, Atmospheric Condition, and Humidity}

The effects of temperature, atmospheric condition, and relative humidity $(\mathrm{RH})$ on the removal of gaseous toluene by the illuminated MLL-53(Fe) were examined; the pseudo first-order rate constants for the toluene removal (bars) and the percent removals after $6 \mathrm{~h}$ treatment (red cycles) are presented for varied conditions (Fig. 4).

Increasing temperature inhibited toluene removal by the illuminated MLL-53(Fe) (Fig. 4(a)). With raising temperature from 20 to $50^{\circ} \mathrm{C}$, the observed removal rate constant and the percent removal decreased by 65.2 and $52.6 \%$, respectively. This result can be ex- plained by the temperature-dependent adsorption capacity of MIL-53(Fe). At higher temperature, the toluene adsorption was lower (Fig. S4(a) of the SD), possibly due to the structural changes of MIL-53(Fe); the dehydration with elevating temperature led to the contraction of pores [52].

The anoxic condition significantly inhibited the removal of toluene by the illuminated MIL-53(Fe) (compare to the toluene removal under air and $\mathrm{O}_{2}$ conditions) (Fig. 4(b)). The toluene removal rate under $\mathrm{N}_{2}$ condition (0.011 $\mathrm{min}^{-1}$ ) was approximately three-fold lower than those under air and $\mathrm{O}_{2}$ conditions. The percent removal of toluene after $6 \mathrm{~h}$ under $\mathrm{N}_{2}$ condition was 34.5\%, which was approximately half of those under air and $\mathrm{O}_{2}$ conditions, of $64-67 \%$. The removal of toluene in dark was also lower under $\mathrm{N}_{2}$ condition (Fig. S4(b) of the SD), suggesting that the lesser adsorption of toluene suppressed the subsequent photocatalytic degradation. The lesser adsorption capacity of toluene under $\mathrm{N}_{2}$ condition may be attributed to the selective binding of $\mathrm{N}_{2}$ onto iron [64, 65], which limits the competitive adsorption of toluene.

Increasing relative humidity inhibited the removal of toluene (Fig. 4(c)). When relative humidity increased from $10 \%$ to $80 \%$, the observed removal rate constant and the percent removal decreased by $33.3 \%$ and $20.2 \%$, respectively. Notably, a different trend was observed for the toluene removal under dark conditions, where the adsorption of toluene increased with increasing relative humidity from $10 \%$ to $50 \%$, then rather decreased at $80 \%$ relative humidity (Fig. S4(c) of the SD). The increased adsorption of toluene in the humidity range of $10-50 \%$ may be a transient phenomenon due to the enlargement of pores by the hydration of MIL-53(Fe) [66]. The exposure to water led to the structural destruction of MIL-53(Fe) (Fig. S5 of the SD), which is believed to be responsible for the decreasing photocatalytic activity (Fig. 4(c)) and the lower 

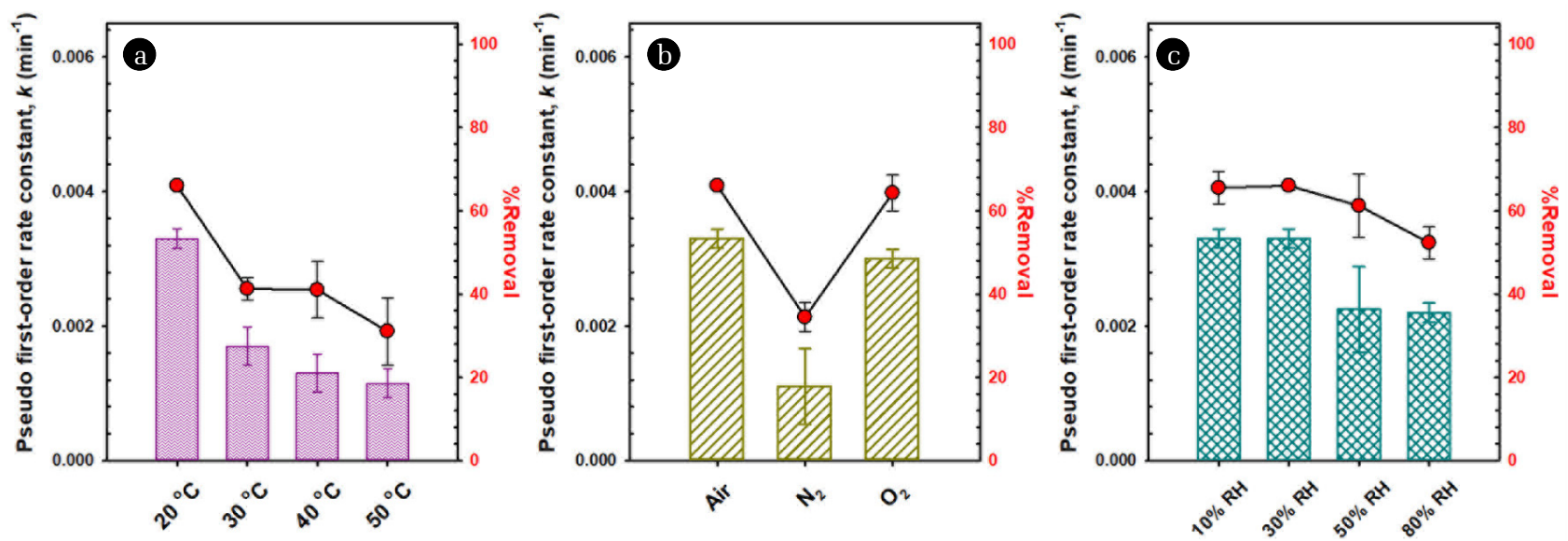

Fig. 4. Effects of (a) temperature, (b) atmospheric condition, and (c) relative humidity on the removal of toluene by illuminated MIL-53(Fe) ([Toluene $]_{0}$ $\left.=3.59 \mathrm{mg} / \mathrm{L} ;[\text { Catalyst }]_{0}=0.15 \mathrm{~g} / \mathrm{mL}\right)$.

adsorption efficiency at $80 \%$ relative humidity (Fig. S4(c) in the $\mathrm{SD})$. The characteristic XRD patterns of $\mathrm{MLL}-53(\mathrm{Fe})$ were distorted by the treatments in $80 \%$ relative humidity air, and in water (Fig. S5(a) of the SD). The peaks for released terephthalic acid were in the HPLC spectrum of the water in which MIL-53(Fe) has been suspended (Fig. S5(b) of the SD). The SEM images successfully visualized the water-induced destruction of MIL-53(Fe) (Figs. S5(c)-(e) of the SD).

\subsection{Reusability of MIL-53(Fe)}

To test the reusability of MLL-53(Fe), the toluene removal by MIL-53(Fe) was examined for five repeated runs under dark and illuminated conditions (Fig. 5). The removal and photochemical reactions were conducted for $6 \mathrm{~h}$ for each run (Fig. 5). Under dark conditions, the toluene adsorption capacity of MIL-53(Fe) was kept constant for the repeated runs (Fig. 5(a)). Even though a slight activity decrease was observed, the photocatalytic activity of MIL-53(Fe) for toluene removal during the repeated use was sustained (Fig. 5(b)).

\subsection{Photocatalytic Viral Inactivation by MIL-53(Fe)}

The photocatalytic inactivation of air-suspended $\Phi X 174$ by MIL-53(Fe) was examined under visible light illumination (Fig. 6(a)). Under dark conditions, the inactivation of $\Phi X 174$ was negligible. The visible light illumination without MIL-53(Fe) resulted in $1.6 \log$ inactivation of $\Phi X 174$ in $1 \mathrm{~h}$ possibly due to the thermal effect; the temperature increased to $30^{\circ} \mathrm{C}$ by $1 \mathrm{~h}$ illumination, and the control experiment confirmed that the temperature elevation to $30^{\circ} \mathrm{C}$ led to more than $1 \log$ inactivation (data not shown). The illuminated ML-53(Fe) inactivated $\Phi X 174$ by 2.9 $\log$ in $1 \mathrm{~h}$, indicating that the photocatalytic reactions contribute to the viral inactivation. The inactivation of $\Phi X 174$ by the illumi-
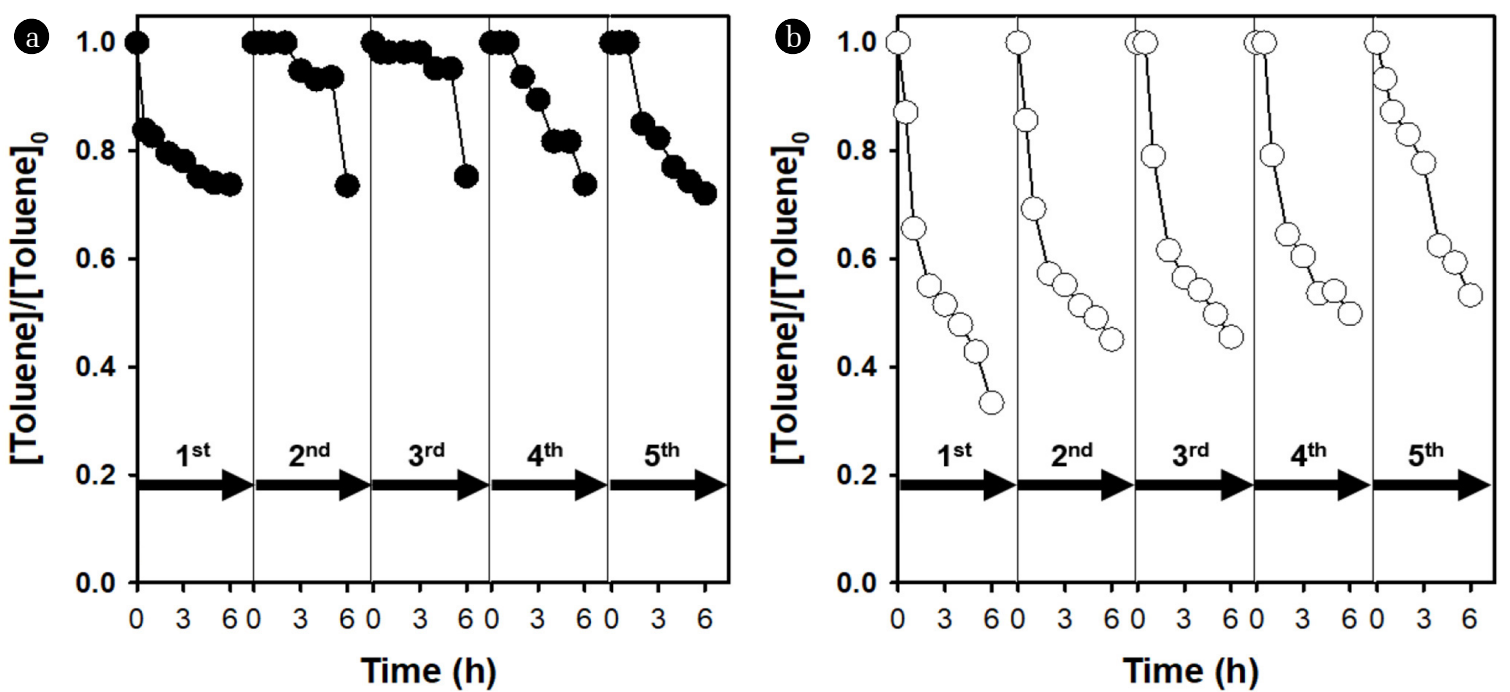

Fig. 5. Repeated removal of toluene by MIL-53(Fe) under (a) dark, and (b) illuminated conditions ([Toluene $]_{0}=3.59 \mathrm{mg} / \mathrm{L}$; $[\text { Catalyst }]_{0}=0.15$ $\mathrm{g} / \mathrm{mL})$. 

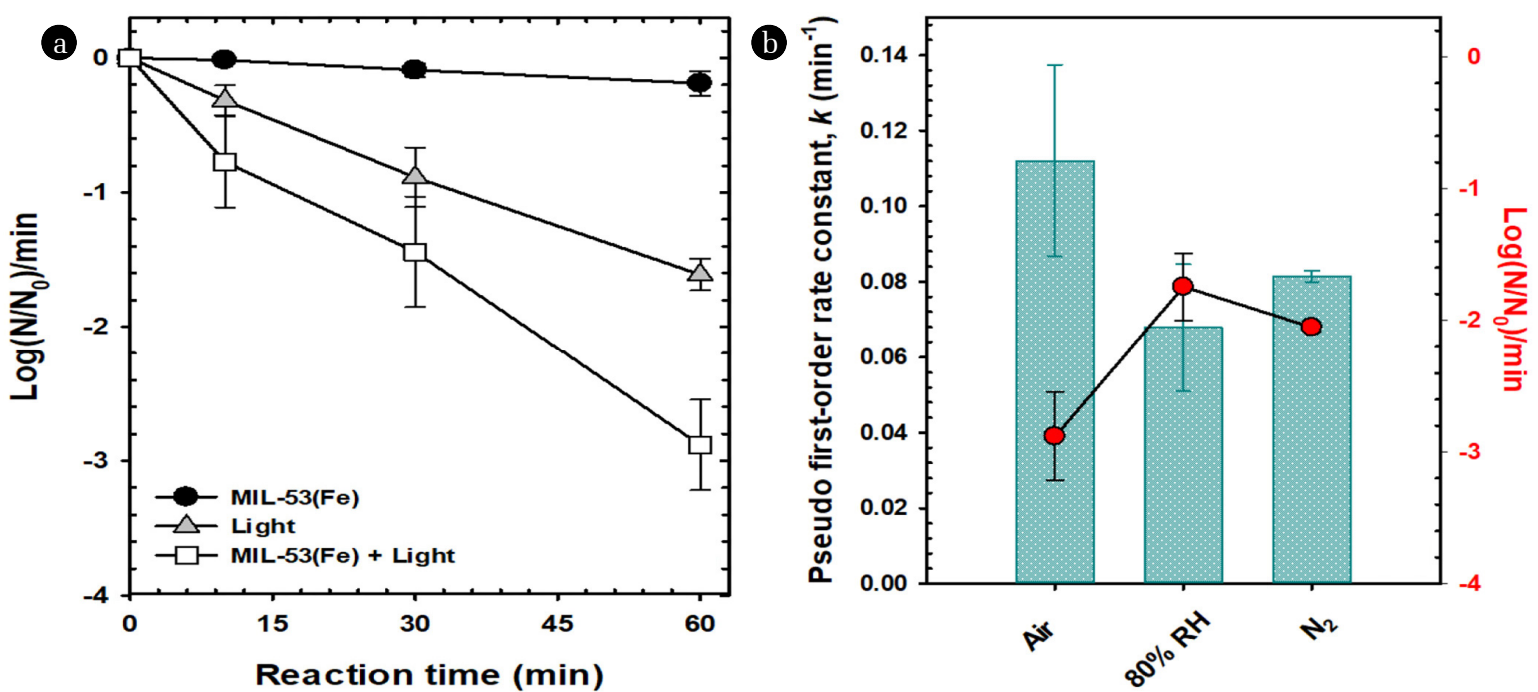

Fig. 6. Inactivation of $\Phi X 174$ by illuminated MIL-53(Fe): (a) time-dependent inactivation curves and (b) inactivation rates under different conditions (air, 80\% relative humidity $\left.\left.(\mathrm{RH}), \mathrm{N}_{2}\right)\left([\Phi \mathrm{X} 174]_{0}=10^{6} \mathrm{PFU} / \mathrm{mL} \text {; [Catalyst }\right]_{0}=0.15 \mathrm{~g} / \mathrm{mL}\right)$.

nated MIL-53(Fe) was examined under $80 \%$ relative humidity and $\mathrm{N}_{2}$ conditions; the average inactivation rate (log inactivation/min) and the log inactivation degree in $1 \mathrm{~h}$ are presented (Fig. 6(b)). Under $80 \%$ relative humidity and $\mathrm{N}_{2}$ conditions, the inactivation of $\Phi X 174$ was suppressed, compared to the ambient condition. This observation is consistent with the effects of relative humidity and nitrogen on the toluene removal (Figs. 4(a) and 4(b)), suggesting that similar photocatalytic mechanisms may be responsible for both the toluene removal and viral inactivation.

\subsection{Photocatalytic Mechanisms}

$\mathrm{ML}-53(\mathrm{Fe})$ is composed of iron-oxo clusters that are linked together by organic ligands (terephthalic acid). The photocatalytic activity of $\mathrm{MLL}-53(\mathrm{Fe})$ is known to mainly result from the excitation of iron-oxo clusters [53, 67]. The pathways for the generation of reactive oxidants by the illuminated ML-53(Fe) can be postulated as follows. Upon visible light illumination, fast charge separation occurs, generating CB electrons and VB holes [53]. The photo-generation of charge carriers was evidenced by PL and transient photocurrent measurements (Figs. S7(a) and S7(b) of the SD); a broad PL peak appeared at around $442 \mathrm{~nm}$, which corresponds to the bandgap energy of ML-53(Fe) $(2.76 \mathrm{eV})$, and the discontinuous light illumination successfully produced responsive alternating photocurrent. The hole oxidation is believed to be mainly responsible for the degradation of toluene, and the inactivation of $\Phi X 174$. The oxidation power of VB holes of photoexcited MLL-53(Fe) $\left(+2.29 \mathrm{~V}_{\mathrm{NHE}}\right.$, Fig. 1(f)) is high enough to destroy toluene; the oxidation potential of toluene is known to be $+1.733 \mathrm{~V}_{\mathrm{NHE}}$ [68]. The generation of hydroxyl radical $(\mathrm{OH})$ by the hole oxidation of water is thermodynamically unfavored $\left(E^{\mathrm{O}}\left[\mathrm{OH} / \mathrm{H}_{2} \mathrm{O}\right]=+2.80 \mathrm{~V}_{\mathrm{NHE}}\right.$, [69]); the EPR analysis failed to detect the DMPO-OH spin adduct (Fig. S6(a) of the SD).

Meanwhile, the CB electrons of MIL-53(Fe) can be trapped by oxygen to yield $\mathrm{O}_{2}{ }^{--}\left(E^{\mathrm{O}}\left[\mathrm{O}_{2} / \mathrm{O}_{2}{ }^{--}\right]=-0.33 \mathrm{~V}_{\mathrm{NHE}}\right.$, [70]); note that the CB level of MIL-53(Fe) was $-0.47 \mathrm{~V}_{\mathrm{NHE}}$ (Fig. 1(f)). Such electron-trapping prevents the electron-hole recombination, enhancing the hole oxidation of toluene. However, in the spectrophotometric measurement using XTT (Fig. S6(b) of the SD), the signal of $\mathrm{O}_{2}{ }^{--}$was not detected, which rules out the possibility of $\mathrm{O}_{2}^{--}$generation in this system.

\section{Conclusions}

ML-53(Fe) synthesized by a simple hydrothermal method exhibited good crystallinity, and high surface area and porosity as well as photocatalytic properties, as confirmed by various characterization methods. Under visible light-illumination, ML-53(Fe) led to toluene removal (by both adsorption and photocatalytic oxidation) and $\Phi X 174$ inactivation in air. The adsorptive and photocatalytic efficacies of MIL-53(Fe) for the control of contaminants were found to be influenced by humidity, temperature, and the presence of $\mathrm{N}_{2}$. These effects are assumed to result from the structural distortion of ML-53(Fe), depending on the conditions. The oxidation by photo-generated holes appears to be the primary pathway for toluene degradation and the inactivation of $\Phi X 174$ by illuminated MIL-53(Fe). No evidence was found for the generation of $\mathrm{OH}$ or $\mathrm{O}_{2}{ }^{-}$. The observations in this study demonstrate that MLL-53(Fe) can be used to improve indoor air quality by controlling VOCs and pathogenic microorganisms. Potential applications of MIL-53(Fe) include photocatalytic air purification systems, and different antimicrobial coatings that are applicable under indoor lighting conditions.

\section{Acknowledgments}

This work was supported by Korea Environment Industry \& Technology Institute (KEITI) through Prospective Green Technology Innovation Project (2020003160008) and by a Korea Medical Device Development Fund grant (HW20C2190). 


\section{Author Contributions}

S.Y.P (M.S. student) conceived and designed the study, performed the experiments, wrote the paper, reviewed and edited the manuscript. J.S. (Ph.D.) conceived, designed the study, and performed the experiments. T.K. (Ph.D. student) performed the experiments and reviewed the manuscript. J.K. (Ph.D. student) performed the experiments, reviewed and edited the manuscript. J.C. (researcher) reviewed the manuscript. C.L. (Associate professor) conceived and designed the study, reviewed and edited the manuscript. All authors read and approved the manuscript.

\section{References}

1. EPA. Volatile organic compounds' impact on indoor air quality [Internet]; 2020 [cited 19 July 2020]. Available from: https://www.epa.gov/indoor-air-quality-iaq/volatile-organiccompounds-impact-indoor-air-quality.

2. Brown S, Sim M, Abramson M, Gray C. Concentrations of volatile organic compounds in indoor air - a review. Indoor Air 1994;4:123-134.

3. Jo W, Park K. Heterogeneous photocatalysis of aromatic and chlorinated volatile organic compounds (VOCs) for non-occupational indoor air application. Chemosphere 2004;57:555-565.

4. Heavner D, Morgan W, Ogden N. Determination of volatile organic compounds and ETS apportionment in 49 homes. Environ. Int. 1995;21:3-21.

5. Shah J, Singh H. Distribution of volatile organic chemicals in outdoor and indoor air. Environ. Sci. Technol. 1988;22:13811388.

6. Wang S, Ang H, Tade M. Volatile organic compounds in indoor environment and photocatalytic oxidation: state of the art. Environ. Int. 2007;33:694-705.

7. Kim Y, Harrad S, Harrison R. Concentrations and sources of VOCs in urban domestic and public microenvironments. Environ. Sci. Technol. 2001;35:997-1004.

8. Jones A. Indoor air quality and health. Atmos. Environ. 1999;33:4535-4564.

9. Plaisance H, Vignau-Laulhere J, Mocho P, Sauvat N, Raulin K, Desauziers V. Volatile organic compounds concentrations during the construction process in newly-built timber-frame houses: sources identification and emission kinetics. Environ. Sci.: Processes Impacts 2017;19:696-710.

10. Tancrede M, Wilson R, Zeise L, Crouch E. The carcinogenic risk of some organic vapors indoors: a theoretical survey. Atmos. Environ. 1987;21:2187-2205.

11. Wallance L, Pellizzari E, Hartwell T, Davis V, Michael L, Whitmore R. The influence of personal activities on exposure to volatile organic compounds. Environ. Res. 1989;50:37-55.

12. Pyankov O, Pyankova O, Agranovski I. Inactivation of airborne influenza virus in the ambient air. J. Aerosol. Sci. 2012;53:21-28.

13. Hermann J, Munoz-Zanzi C, Zimmerman J. A method to provide improved dose-response estimates for airborne pathogens in animals: An example using porcine reproductive and respiratory syndrome virus. Vet. Microbiol. 2009;133:297-302.

14. Nikitin N, Petrova E, Trifonova E, Karpova O. Influenza virus aerosols in the air and their infectiousness. Advances in virology 2014.

15. Rosa G, Frantini M, Libera S, Iaconelli M, Muscillo M. Viral infections acquired indoors through airborne, droplet or contact transmission. Ann Ist Super Sanita 2013;49:124-132.

16. Sattar S, Bact D. Indoor air as a vehicle for human pathogens: Introduction, objectives, and expectation of outcome. Am. J. Infect. Control 2016;44:S95-S101.

17. Peng S, Deng Y, Li W, Chen J, Liu H, Chen Y. Aminated mesoporous silica nanoparticles for removal of low-concentration aldehyde malodorous gases. Environ. Sci. Nano 2018;5:26632671.

18. Zhao X, Ma Q, Lu G. VOC removal: Comparison of MCM-41 with hydrophobic zeolites and activated carbon. Energy Fuels 1998;12:1051-1054.

19. Lelicinska-Serafin K, Rolewicz-Kalinska A, Manczarski P. VOC removal performance of a joint process coupling biofiltration and membrane-filtration treating food industry waste gas. Int. J. Environ. Res. Public Health 2019;16:3009.

20. Habibi A, Asadzadeh S, Feizpoor S, Rouhi A. Review on heterogeneous photocatalytic disinfection of waterborne, airborne, and foodborne viruses: Can we against pathogenic viruses?. J. Colloid Interface Sci. 2020;580:503-514.

21. Kim S, Hwang H, Hong S, Photocatalytic degradation of volatile organic compounds at the gas-solid interface of a $\mathrm{TiO}_{2}$ photocatalyst. Chemosphere 2002;48:437-444.

22. Fu X, Zeltner W, Anderson M. The gas-phase photocatalytic mineralization of benzene on porous titania-based catalysts. Appl. Catal. B-Environ. 1995;6:209-224.

23. Hussain M, Russo N, Saracco G. Photocatalytic abatement of VOCs by novel optimized $\mathrm{TiO}_{2}$ nanoparticles. Chem. Eng. J. 2011;166:138-149.

24. Moulis F, Krysa J. Photocatalytic degradation of several VOCs (n-hexane, n-butyl acetate and toluene) on $\mathrm{TiO}_{2}$ layer in a closed-loop reactor. Catal. Today 2013;209:153-158.

25. Bianchi C, Gatto S, Pirola C, et al. Photocatalytic degradation of acetone, acetaldehyde and toluene in gas-phase: comparison between nano and micro-sized $\mathrm{TiO}_{2}$. Appl. Catal. B-Environ. 2014;146:123-130.

26. Weon $\mathrm{S}$, Choi W. $\mathrm{TiO}_{2}$ nanotubes with open channels as deactivation-resistant photocatalyst for the degradation of volatile organic compounds. Environ. Sci. Technol. 2016;50:2556-2563.

27. Weon S, Choi E, Kim H, et al. Active $\{001\}$ facet exposed $\mathrm{TiO}_{2}$ nanotubes photocatalyst filter for volatile organic compounds removal: from material development to commercial indoor air cleaner application. Environ. Sci. Technol. 2018;52:9330-9340.

28. Weon S, Kim J, Choi W. Dual-components modified $\mathrm{TiO}_{2}$ with $\mathrm{Pt}$ and fluoride as deactivation-resistant photocatalyst for the degradation of volatile organic compound. Appl. Catal. B-Environ. 2018;220:1-8.

29. Pelaez M, Nolan N, Pillai S, et al. A review on the visible light active titanium dioxide photocatalysts for environmental applications. Appl. Catal. B-environ. 2012;125:331-349.

30. Arai T, Horiguchi M, Yanagida M, Gunji T, Sugihara H, Sayama $\mathrm{K}$. Complete oxidation of acetaldehyde and toluene over a $\mathrm{Pd} / \mathrm{WO}_{3}$ photocatalyst under fluorescent- or visible-light 
irradiation. Chem. Commun. 2008;43:5565-5567.

31. Katsumata K, Motoyoshi R, Matsushita N, Okada K. Preparation of graphitic carbon nitride $\left(\mathrm{g}-\mathrm{C}_{3} \mathrm{~N}_{4}\right) / \mathrm{WO}_{3}$ composites and enhanced visible-light-driven photodegradation of acetaldehyde gas. J. Hazard. Mater. 2013;260:475-482.

32. Zhang $\mathrm{L}$, Qin $\mathrm{M}, \mathrm{Yu} \mathrm{W}$, et al. Heterostructured $\mathrm{TiO}_{2} / \mathrm{WO}_{3}$ nanocomposites for photocatalytic degradation of toluene under visible light. J. Electrochem. Soc. 2017;164:H1086-H1090.

33. Asadzadeh S, Habibi A. g- $\mathrm{C}_{3} \mathrm{~N}_{4} /$ carbon dot-based nanocomposites serve as efficacious photocatalysts for environmental purification and energy generation: A review. J. Clean. Prod. 2020;276:124319

34. Liu B, Li X, Zhao Q, et al. Insight into the mechanism of photocatalytic degradation of gaseous $O$-dichlorobenzene over flower-type $\mathrm{V}_{2} \mathrm{O}_{5}$ hollow spheres. J. Mater. Chem. A 2015;3:1516315170.

35. Zhang F, Li X, Zhao Q, Zhang D. Rational design of $\mathrm{ZnFe}_{2} \mathrm{O}_{4} / \mathrm{In}_{2} \mathrm{O}_{3}$ nanoheterostructures: Efficient photocatalyst for gaseous 1,2-dichlorobenzene degradation and mechanistic insight. ACS Sus. Chem. Eng. 2016;4;9:4554-4562.

36. Zhang F, Li X, Zhao Q, Chen A. Facile and controllable modification of $3 \mathrm{D} \mathrm{In}_{2} \mathrm{O}_{3}$ microflowers with $\mathrm{In}_{2} \mathrm{~S}_{3}$ nanoflakes for efficient photocatalytic degradation of gaseous ortho-dichlorobenzene. J. Phys. Chem. C 2016;120;34:19113-19123.

37. Gargia H, Navalon S. Metal-organic frameworks: Applications in separations and catalysis. 1st ed. Germany: Wiley-VCH Verlag $\mathrm{GmbH}$ \& Co. KGaA.; 2018.

38. Qiu J, Zhang X, Feng Y, Zhang X, Wang H, Yao J. Modified metal-organic frameworks as photocatalysts. Appl. Catal. B-Environ. 2018;231:317-342.

39. Chae H, Siberio-perez D, Kim J, et al. A route to high surface area, porosity and inclusion of large molecules in crystals. Nature 2004;427:523-527.

40. Wong-Foy A, Matzger A, Yaghi O. Exceptional $\mathrm{H}_{2}$ saturation uptake in microporous metal-organic frameworks. J. Am. Chem. Soc. 2006;128:3494-3495.

41. Zhao Z, Li Z, Lin Y. Adsorption and diffusion of carbon dioxide on metal-organic framework (MOF-5). Ind. Eng. Chem. Res. 2009;48:10015-10020.

42. Sun D, Ye L, Li Z. Visible-light-assisted aerobic photocatalytic oxidation of amines to imines over $\mathrm{NH}_{2}-\mathrm{MLL}-125(\mathrm{Ti})$. Appl. Catal. B-Environ.2015;164:428-432.

43. Xu W, Ma L, Ke F, et al. Metal-organic frameworks ML-88A hexagonal microrods as a new photocatalyst for efficient decolorization of methylene blue dye. Dalton Trans. 2014;43: 3792-3798.

44. Fu Y, Sun L, Yang H, Xu L, Zhang F, Zhu W. Visible-light-induced aerobic photocatalytic oxidation of aromatic alcohols to aldehydes over Ni-doped $\mathrm{NH}_{2}$-MIL-125(Ti). Appl. Catal. B-Environ. 2016;187:212-217.

45. Zhang Z, Li X, Liu B, Zhao Q, Chen G. Hexagonal microspindle of $\mathrm{NH}_{2}$-MIL-101(Fe) metal-organic frameworks with visible-light-induced photocatalytic activity for the degradation of toluene. RSC Adv. 2016;6:4289-4295.

46. Li P, Kim S, Jin J, Chun D, Park J. Efficient photodegradation of volatile organic compounds by iron-based metal-organic frameworks with high adsorption capacity. Appl. Catal.
B-Environ. 2020;263:118284.

47. Li P, Li J, Feng X, et al. Metal-organic frameworks with photocatalytic bactericidal activity for integrated air cleaning. Nat. Commun.2019;10:1-10.

48. Bourrelly S, Llewellyn P, Serre C, Millange F, Loiseau T, Ferey G. Different adsorption behaviors of methane and carbon dioxide in the isotypic nanoporous metal terephthalates MIL-53 and MIL-47. J. Am. Chem. Soc. 2005;127:13519-13521.

49. Horcajada P, Serre C, Maurin G, et al. Flexible porous metal-organic frameworks for a controlled drug delivery. J. Am. Chem. Soc. 2008;130:6774-6780.

50. Trung T, Trens P, Tanchoux N, et al. Hydrocarbon adsorption in the flexible metal organic frameworks ML-53(Al, Cr). J. Am. Chem. Soc. 2008;130:16926-16932.

51. Loiseau T, Serre C, Huguenard C, et al. A rationale for the large breathing of the porous aluminum terephthalate(MIL-53) upon hydration. Chem. Eur. J. 2004;10:1373-1382.

52. Millange F, Guillou N, Walton F, Greneche J, Margiolake I, Ferey G. Effect of the nature of the metal on the breathing steps in MOFs with dynamic frameworks. Chem. Comm. 2008;4732-4734.

53. Liang R, Jing F, Shen L, Qin N, Wu L. MLL-53(Fe) as a highly efficient bifunctional photocatalyst for the simultaneous reduction of $\mathrm{Cr}(\mathrm{VI})$ and oxidation of dyes. J. Hazard. Mater. 2015;287:364-372.

54. Ai L, Zhang C, Jiang J. Iron terephthalate metal-organic framework: revealing the effective activation of hydrogen peroxide for the degradation of organic dye under visible light irradiation. Appl. Catal. B-Environ. 2014;148-149:191-200.

55. Gao Y, Li S, Li Y, Yao L, Zhang H. Accelerated photocatalytic degradation of organic pollutant over metal-organic framework MIL-53(Fe) under visible LED light mediated by persulfate. Appl. Catal. B-Environ. 2017;202:165-174.

56. ATCC manual; 2009 [cited 19 July 2020]. Available from: https://www.atcc.org/ /media/4FF52CABAD564420ACF0BC A4FE4DF284.ashx, 2020.

57. Zhao K, Zhang X, Zhang L. The first BiOI-based solar cells. Electrochem. Comm. 2009;11:612-615.

58. Brunet L, Lyon D, Hotze E, Alvarez P, Wiesner M. Comparative photoactivity and antibacterial properties of $\mathrm{C}_{60}$ fullerenes and titanium dioxide nanoparticles. Environ. Sci. Technol. 2009;43:4355-4360.

59. Gong C, Chen D, Jiao X, Wang Q. Continuous hollow $\alpha-\mathrm{Fe}_{2} \mathrm{O}_{3}$ and $\alpha$-Fe fibers prepared by the sol-gel method. J. Mater. Chem. 2002;12:1844-1847.

60. Lopez R, Gomez R. Band-gap energy estimation from diffuse reflectance measurements on sol-gel and commercial $\mathrm{TiO}_{2}$ : a comparative study. J. Sol-Gel Sci. Technol. 2012;61:1-7.

61. Yang Z, Xu X, Liang X, et al. MIL-53(Fe)-graphene nanocomposites: efficient visible-light photocatalysts for the selective oxidation of alcohols. Appl. Catal. B-Environ. 2016;198: 112-123.

62. Sepulveda-Guzman S, Lara L, Perez-Camacho O, Rodrigruez-Fernandez O, Olivas A, Escudero R. Synthesis and characterization of an iron oxide poly(styrene-co-carboxybutylmaleimide) ferrimagnetic composite. Polymer 2007;48: 720-727. 
63. Sharma N, Sharma N, Srinivasan P, Kumar S, Rayappan J, Kailasam K. Heptazine based organic framework as a chemiresistive sensor for ammonia detection at room temperature. J. Mater. Chem. A 2018;6:18389-18395.

64. Parkes M, Greathouse J, Hart D, Gallis D, Nenoff T. Ab initio molecular dynamics determination of competitive $\mathrm{O}_{2}$ vs. $\mathrm{N}_{2}$ adsorption at oopen metal sites of $\mathrm{M}_{2}$ (dobdc). Phys. Chem. Chem. Phys. 2016;18:11528-11538.

65. Ponec V, Knor Z. On the forms of nitrogen adsorbed on iron. J. Catal. 1968;10:73-82.

66. Munn A, Ramirez-Cuexta A, Millange F, Walton R. Interaction of methanol with the flexible metal-organic framework MIL-53(FE) observed by inelastic neutron scattering. Chem. Phys. 2013;427:30-37.
67. Laurier K, Vermoortele F, Ameloot R, Vos D, Hofkens J, Roeffaers M. Iron(III)-based metal-organic frameworks as visible light photocatalysts. J. Am. Chem. Soc. 2013;135:14488-14491.

68. Fuchigami T, Atobe M, Inagi S. Appendix B, Tables of physical data. In: Fundamentals and applications of organic electrochemistry: Synthesis, materials, devices. 1st ed. United Kingdom: John Wiley \& Sons, Ltd.; 2015, p.230-235.

69. Buxton G, Greenstock C, Helman W, Ross A. Critical review of rate constants for reactions of hydrated electrons, hydrogen atoms and hydroxyl radicals $\left(\cdot \mathrm{OH} / \bullet^{-}\right)$in aqueous solution. J. Phys. Chem. Ref. Data 1988;17:513-886.

70. Wardman P. Reduction potentials of one-electron couples involving free radicals in aqueous solution. J. Phys. Chem. Ref. Data 1989;18:1637-1755. 